This document was prepared in conjunction with work accomplished under Contract No. DE-AC09-96SR18500 with the U. S. Department of Energy.

\title{
DISCLAIMER
}

This report was prepared as an account of work sponsored by an agency of the United States Government. Neither the United States Government nor any agency thereof, nor any of their employees, nor any of their contractors, subcontractors or their employees, makes any warranty, express or implied, or assumes any legal liability or responsibility for the accuracy, completeness, or any third party's use or the results of such use of any information, apparatus, product, or process disclosed, or represents that its use would not infringe privately owned rights. Reference herein to any specific commercial product, process, or service by trade name, trademark, manufacturer, or otherwise, does not necessarily constitute or imply its endorsement, recommendation, or favoring by the United States Government or any agency thereof or its contractors or subcontractors. The views and opinions of authors expressed herein do not necessarily state or reflect those of the United States Government or any agency thereof. 


\section{The Role of Ceramics in a Resurgent Nuclear Industry}

by

JOHN MARRA

Westinghouse Savannah River Company

Savannah River Site

Aiken, South Carolina 29808

Additional Authors:

This paper was prepared in connection with work done under the above contract number with the U. S. Department of Energy. By acceptance of this paper, the publisher and/or recipient acknowledges the U. S. Government's right to retain a nonexclusive, royalty-free license in and to any copyright covering this paper, along with the right to reproduce and to authorize others to reproduce all or part of the copyrighted paper. 
John Marra

Savannah River National Laboratory

Aiken, SC 29802 USA

Charles Henager, Jr.

Pacific Northwest National Laboratory

Richland, WA 99352 USA

William Lee

Imperial College London

London, England SW7 2AZ UK

Kurt Sickafus

Los Alamos National Laboratory

Los Alamos, NM 87545 USA

Steven Zinkle

Oak Ridge National Laboratory

Oak Ridge, TN 37831 USA

\section{EXECUTIVE SUMMARY}

With fuel oil and natural gas prices near record highs and worldwide energy demands increasing at an alarming rate, there is growing interest in revitalization of the nuclear power industry within the United States and across the globe. Ceramic materials have long played a very important part in the commercial nuclear industry with applications throughout the entire fuel cycle; from fuel fabrication to waste stabilization. As the international community begins to look at advanced fuel cycles that minimize waste and increase proliferation resistance, ceramic materials will play an even larger role. Many of the advanced reactor concepts being evaluated operate at high-temperature requiring the use of durable, heat-resistant materials. Ceramic fuels are being investigated for a variety of Generation IV reactor concepts. These include the traditional TRISO-coated particles as well as advanced inert-matrix fuels. In order to minimize wastes and legacy materials, ceramic processes are also being applied to fuel reprocessing operations. Ceramic materials continue to provide a vital contribution in 'closing the fuel cycle' by stabilization of associated low-level and high-level wastes in highly durable grout, ceramics, and glass. In the next five years, programs that are currently in the conceptual phase will begin laboratory- and engineering-scale demonstrations. This will require production-scale demonstrations of several ceramic technologies from fuel form development to advanced stabilization methods. Within the next five to ten years, these demonstrations will move to even larger scales and will also include radioactive demonstrations of these advanced technologies. These radioactive demonstrations are critical to program success and will require advances in ceramic materials associated with nuclear energy applications. 


\section{HISTORY, CURRENT, AND FUTURE TECHNOLOGY}

Energy is the fuel of national prosperity. As countries emerge and develop, energy demand increases with increasing gross domestic product (GDP). Figure 1 shows this trend for both mature and emerging markets. Associated with this growth, worldwide energy demand

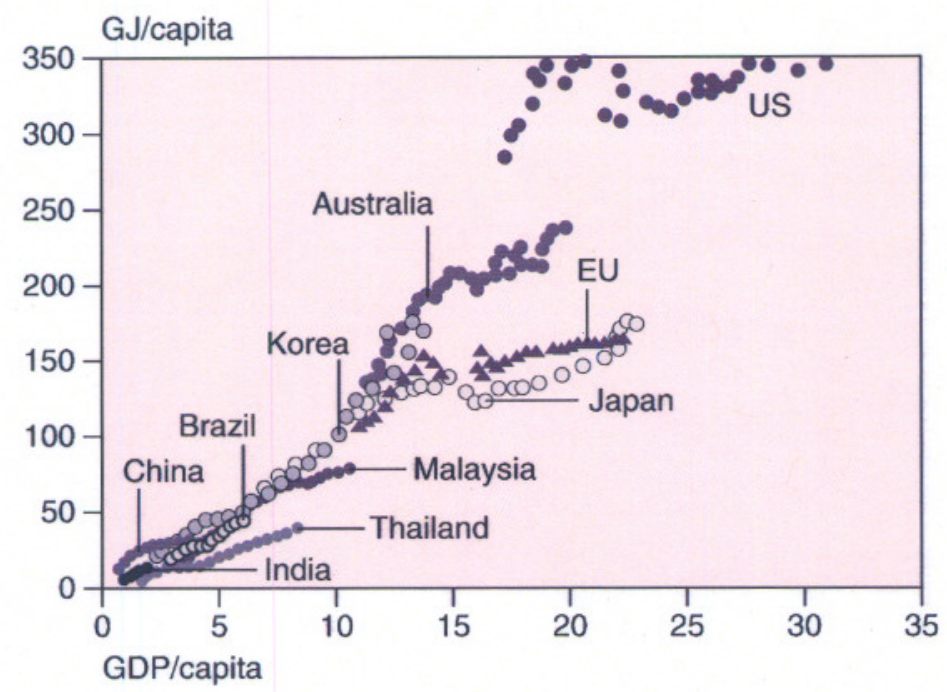

Figure 1 - Energy consumption as a function of gross domestic product (GDP). [Source - Royal Dutch Shell, "Exploring the Future - Energy Needs, Choices and Possibilities, Scenarios to 2050," 2001.]

continues to grow at unprecedented rates. As shown in Table 1, worldwide energy consumption is predicted to grow at an annual rate of $2.6 \%$ between now and 2025 with the majority of this growth occurring in 'transitional' or 'emerging' economies. To keep up with the increasing demand, emerging economies are increasing their reliance on nuclear energy. Major nuclear projects are underway across the globe, particularly in India and China.

Table 1 - World net electricity and nuclear energy consumption by region, 1990-2025 (Billion Kilowatt-hours)

\begin{tabular}{lcccccccc} 
& \multicolumn{3}{c}{ History } & \multicolumn{3}{c}{ Projections } & Avg. Annual \\
\multicolumn{1}{c}{ Region/Country } & $\mathbf{1 9 9 0}$ & $\mathbf{2 0 0 1}$ & $\mathbf{2 0 0 2}$ & $\mathbf{2 0 1 0}$ & $\mathbf{2 0 1 5}$ & $\mathbf{2 0 2 0}$ & $\mathbf{2 0 2 5}$ & Change (\%) \\
\hline \hline Electricity Consumption & & & & & & & & \\
Mature Economies & 6368 & 7934 & 8086 & 9079 & 9837 & 10514 & 11319 & 1.5 \\
Transitional Economies & 1906 & 1520 & 1544 & 2334 & 2654 & 2917 & 3145 & 3.1 \\
Emerging Economies & 2272 & 4383 & 4645 & 7462 & 8909 & 10246 & 11554 & 4.0 \\
Total World & 10546 & 13836 & 14275 & 18875 & 21400 & 23677 & 26018 & 2.6 \\
& & & & & & & & \\
Nuclear Energy Consumption & & & & & & & & \\
Mature Economies & 1544 & 2024 & 2032 & 2120 & 2136 & 2110 & 2083 & 0.1 \\
Transitional Economies & 256 & 282 & 302 & 364 & 376 & 437 & 512 & 2.3 \\
Emerging Economies & 105 & 209 & 225 & 406 & 519 & 605 & 675 & 4.9 \\
Total World & 1905 & 2515 & 2560 & 2890 & 3032 & 3152 & 3270 & 1.1
\end{tabular}

[Source - United States Department of Energy, “International Energy Outlook 2005,” DOE/EIA-0484, July 2005] 
This increase in nuclear energy usage has revitalized interest in advanced fuel cycles that minimize waste and increase proliferation resistance. This focus on next generation nuclear power will expand the use of ceramic materials in the nuclear fuel cycle.

Surprisingly to some, ceramics play a critical role in the nuclear cycle, from the high density concrete for the reactor containment systems, to the oxide-based uranium that fuels the fission process, to the glasses, crystalline ceramics, and cements that safely encapsulate nuclear waste products. Beyond some of these well-known applications, ceramic materials have also been widely used to fuel deep-space missions. Since 1961, the US has successfully launched over 25 power systems for space navigational, meteorological, lunar, and planetary missions that have been powered by the decay heat of ceramic ${ }^{238} \mathrm{Pu}$ oxide in radioisotopic thermoelectric generators (RTGs). In the future, ceramic fuels will play an important role in space-based reactor systems. Beyond that, fusion energy will depend on lithium-based ceramics to produce tritium that fuels the fusion plasma, while other ceramics will contain and control the hot plasma. All the while, ceramics and ceramic-related processes continue to find applications in the management of wastes and byproducts produced by these processes.

\section{Nuclear Fuels}

Ceramic fuels play a major role in the generation of electrical power from heat produced by nuclear fission and in special applications by radioactive decay. Ceramic fuels offer higher melting temperatures, chemical compatibility with cladding materials, improved resistance to corrosion, and dimensional stability combined with fission product retention during irradiation. These properties of ceramics provide for an increase margin of safety over metallic fuels, even with their higher thermal conductivity and ease of fabrication. Besides, many ceramic fuels are readily fabricated in quantity by production techniques at a reasonable cost.

Ceramic fuels of uranium, thorium and/or plutonium are fabricated as oxides, carbides and nitrides. Currently, for light-water (LWR and pressurized-water reactor (PWR) systems, the most commonly used ceramic fuel is uranium dioxide $\left(\mathrm{UO}_{2}\right)$, which was first used in the early experiments for the first self sustaining chain reaction at Chicago in 1942, and later as the fuel in the first power reactor at Shippingport in 1954. Most of the power reactors in the world today are fueled with $\mathrm{UO}_{2}$.

Various processing techniques have successfully produced $\mathrm{UO}_{2}$ fuels as wells as $\mathrm{PuO}_{2}$, $\mathrm{ThO}_{2}$, and the various combinations of mixed oxides. All of these dioxides have a face centered cubic crystal structure with no phase changes from room temperature to their melting point $\left(>2450^{\circ} \mathrm{C}\right)$. Phase changes and their associated volume changes in brittle materials such as these ceramics generally cause localized stresses that can lead to cracking. The absence of any phase change not only facilitates fuel fabrication, but also enhances the integrity of the fuel by minimizing the impact of temperature changes during processing, encapsulation, final assembly, transport and end use.

For power reactors, $\mathrm{UO}_{2}$ fuels pellets are commonly fabricated by conventional cold pressing and sintering techniques. The sintered pellets are machined to sized, inspected and then encapsulated in Zircalloy or stainless steel cladding to form fuel rods. The rods then are 
assembled or bundled for loading into the nuclear reactor. Various reactor operational problems have been overcome by controlling the microstructure and chemistry of the fuel. For example, the dimensional stability of the fuel during irradiation can be controlled by coarsening the residual $(\sim 6 \%)$ porosity of the fuel during fabrication by compacting milled powder, followed by granulation and repressing prior to sintering.

Tri-isotropic (TRISO) fuels were originally developed in Germany for high-temperature gas-cooled reactors. In TRISO fuels, uranium carbide or oxide is usually coated in several layers of pyrolytic carbon and silicon carbide, and a porous carbon buffer (see Figure 2) to retain fission products at elevated temperatures. The resulting product resembles black beads the size of salt grains. These particles are molded into graphite pebbles (for pebble bed reactors) or into graphite fuel rods (for prismatic core gas cooled reactors). Active research is underway to determine the best ways to produce uranium-oxide and plutonium-oxide kernels, using an internal gelation process similar to the sol-gel process. The goal is to create fuel beads that allow reactors to operate at higher temperatures so that they can more efficiently convert their heat to electricity. The coated fuel also acts as a miniature containment system that would prevent the release of fission products to the environment during a highly unlikely loss-of-coolant accident.

TRISO fuel would also be used in the Advanced High Temperature Reactor, a long-term concept being developed by the US Department of Energy (DOE). Using molten salts as a coolant, this highly efficient, power-producing reactor would deliver heat at a high enough temperature to produce hydrogen from water more cheaply than electrolysis. This efficient source of hydrogen will be used for automotive applications and building fuel cells.

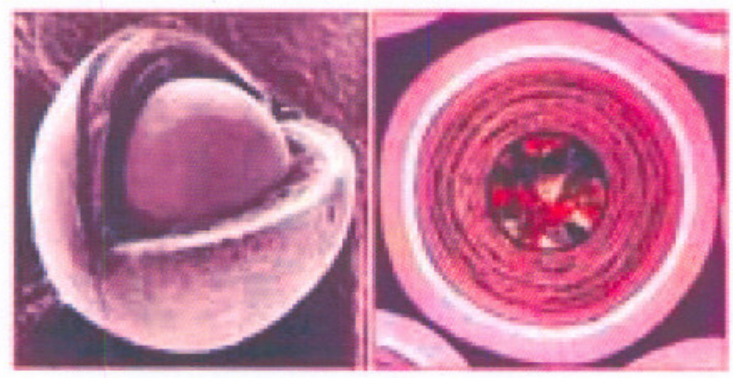

Figure 2 - SEM photomicrographs showing the coating structure of a typical TRISO particle. ${ }^{1}$

As the use of nuclear power becomes more widespread, security risks increase as a direct result of an increasing plutonium stockpile. ${ }^{2}$ To address these concerns, the recently announced Global Nuclear Energy Partnership (GNEP, see http://www.gnep.energy.gov/) program, and in particular the Advanced Fuel Cycle Initiative (AFCI), are developing a technology base to demonstrate advanced fuel cycles that offer inherent proliferation resistance. Inert matrix fuels (IMFs) are being considered for use in three distinct fuel cycle concepts, ${ }^{3}$ namely burning of $\mathrm{Pu}$ in existing LWRs, Pu burning in fast reactors, and the transmutation of minor actinides. Since the latter two scenarios involve the construction of advanced facilities, and the first scenario makes use of existing reactors, the concepts can be thought of as ordered chronologically in terms of potential implementation. 
Simply put, and inert matrix fuels is a material that burns $\mathrm{Pu}$ and other actinides without breed $\mathrm{Pu}$ (or other actinide materials). Therefore, IMFs can be used to produce energy while beneficially eliminating actinide excesses. There are two major categories of IMFs: 'non-fertile' fuels which do not contain uranium and produce no fissionable isotopes and 'low-fertile' fuels that contain uranium and, therefore, breed $\mathrm{Pu}$ and other minor actinides. A variety of ceramic materials have properties making them attractive for IMFs (see Table 2). Each of these properties must be accounted for when designing an IMF for any given application. For example, $\mathrm{ZrO}_{2}$ is very difficult to reprocess and is considered proliferation resistant, making it a desirable candidate for a 'once-though' IMF (i.e., the fuel is not recycled after use). However, this property would clearly hinder use of $\mathrm{ZrO}_{2}$ in an advanced fuel cycle relying on reprocessing and continuous 'burn-down' of fuel materials.

Table 2 - Material properties of several ceramic materials for inert matrix fuels.

\begin{tabular}{lcccccccc} 
& $\mathbf{Z r O}_{2}$ & $\mathbf{M g O}$ & $\mathbf{M g A l}_{2} \mathbf{O}_{4}$ & $\mathbf{A}_{2} \mathbf{B}_{2} \mathbf{O}_{7}$ & NiAl & RuAl & TiN & ZrN \\
\hline \hline Melting Point $\left({ }^{\circ} \mathrm{C}\right)$ & 2675 & 2832 & 2135 & $\sim 2200$ & 1638 & 2050 & 2930 & 2980 \\
$\begin{array}{l}\text { Thermal } \\
\text { Conductivity }\end{array}$ & $\sim 4$ & $\sim 10$ & 5.9 & $1.5-$ & 80 & $50-70$ & $\sim 19$ & $\sim 11-24$ \\
$(\mathrm{~W} / \mathrm{mK})$ & & & & 2.5 & & & & \\
$\begin{array}{l}\text { Thermal Expansion } \\
\left(\mathrm{x} 10^{-6} /{ }^{\circ} \mathrm{C}\right)\end{array}$ & $7.5-13$ & $\sim 13.5$ & $\sim 7.5$ & $\sim 8-11$ & $12-15$ & $5.5-11$ & 9.4 & $6.5-11$ \\
Heat Capacity & 78 & 317 & 190 & $\sim 280$ & $<60$ & & 55 & 55
\end{tabular}

(@1000 $\mathrm{C}, \mathrm{J} / \mathrm{mol} \cdot \mathrm{K})$

$\begin{array}{llllcc}\text { Fabricability } & \text { Standard Cold Press \& Sinter Technique } & \text { Variety of Methods } & \text { Sintering Aids, Hot Press } \\ \text { Reprocessibility } & \text { Poor } \quad \text { Good } & \text { Poor } & \text { Poor } & \text { Good } & \text { Reasonable }\end{array}$

(Proliferation

Resistance $^{-1}$ )

\section{Nuclear Waste Stabilization}

Glass is now the material of choice for incorporating and immobilizing the potentially hazardous radionuclides in high-level nuclear wastes (HLW). Factors that contribute to the suitability of glass waste forms fall into two main categories. First, glass waste forms possess good product durability. Various glass systems have demonstrated the capability of incorporating a variety of waste compositions into durable waste forms. These forms have demonstrated good chemical and mechanical performance as well as good radiation and thermal stability. Second, waste-glass forms possess good processing characteristics. The technology for making waste-glass forms is both well developed and well demonstrated. Waste-glass forms ranging in size from bench- and laboratory-scale products to multi-ton canisters have been successfully produced by using ceramic melters as well as in-can melting techniques. Wasteglass forms have also been produced for a variety of simulated as well as actual radioactive 
wastes. Full-scale high-level waste immobilization by vitrification began at the US Department of Energy's (DOE) Savannah River Site (SRS) in South Carolina in early 1996 and to date, over 8-million pounds of radioactive waste glass have been produced.

The strategy that has been adopted by DOE for long-term management of high-level radioactive waste involves removing the waste from temporary storage facilities, volume reducing it when possible, pre-treating the waste as necessary, and then immobilizing potentially hazardous radionuclides into solid, non-dispersible forms. The waste forms are temporarily stored on-site at the vitrification facility, but are eventually slated to be shipped to a carefully selected and controlled geologic repository. In the US, a variety of waste forms were considered for the existing HLW. Based on product performance and processing characteristics, borosilicate glass is the preferred host matrix for immobilizing HLW.

The vitrification facility at SRS is the largest radioactive waste processing facility in the world. The waste was generated during the recovery of plutonium and uranium from spent reactor fuel and consists of over 40 different elements. Prior to storage in underground carbon steel tanks, the waste is neutralized with sodium hydroxide. As a result, a thick, gelatinous sludge settles on the bottom of the tanks. It contains numerous radioactive elements, as well as compounds of aluminum, iron, and manganese. The other main waste component is salt solution called supernate consisting mainly of sodium nitrate and sodium nitrite and radioactive ${ }^{137} \mathrm{Cs}$ which is highly soluble. The process of making waste glass at the SRS first involves separating radioactive from non-radioactive elements. This ensures that it is mainly hazardous waste that ends up being vitrified and sent to the repository. The non-hazardous component can then be disposed of by simpler, less costly methods such as cement stabilization (see below). At the vitrification facility, the waste is further treated and mixed with ground borosilicate glass frit and sent to a Joule-heated melter. Operating at $\sim 1200{ }^{\circ} \mathrm{C}$, the melter turns a gallon of the waste slurry into $\sim 4$ pounds of vitrified waste, at a rate up to 230 pounds/hour. The molten waste glass exits the melter into large stainless steel canisters. The canisters, 2 feet in diameter and 10 feet high, hold $\sim 3,700$ pounds of waste glass. After filling, the canisters are blasted with a slurry of glass frit to decontaminate them and sealed by welding a steel plug into the neck of the canister. The canisters are temporarily stored at the vitrification facility prior to eventual transport to a geologic repository.

Cement and cement-based materials also provide a simple and cost effective means of waste stabilization and are widely used for low-level waste treatment. Common advantages of cement stabilization include; continuous or batch processing at ambient temperatures, low-cost raw materials, suitability for large or small volumes of many different waste types, and ability to use modular equipment.

Waste stabilization/solidification is most commonly accomplished by mixing aqueousbased wastes with hydraulic materials such as Portland cements, calcium aluminate cements, calcium alumino sulfate cements, magnesium (aluminum) phosphate cements, kiln dusts, fly ashes, reactive slag, etc. Theses materials react with water to form insoluble binders. The hydrated binder phases encapsulate solid particles in the waste, co-precipitate selected contaminant species, and adsorb excess water and soluble contaminants. In addition, the 
aqueous chemistry of the cement-waste mixture can be adjusted so that the soluble contaminants are precipitated from solution simultaneously with the formation of the matrix phases.

Mixtures of the cementitious ingredients plus other special additives, such as, sodium silicate (hardening agent) and set accelerators and retarders are commonly used. As a result, a monolithic waste form can be produced at ambient temperatures. The waste forms can also be designed to have a wide range of properties. Compressive strengths typically range from 503000 psi. Viscosity and set time can also be adjusted to meet mixing and placement requirements dictated by the production process.

Hydrated waste forms are typically used for stabilizing aqueous wastes, such as, condensed off gas wastes, electroplating sludges, salt solutions, incinerator ash, electrostatic precipitator and bag house wastes, and process residues, such as, metal chloride and hydroxide bottoms from ore refining processes. Cementitious materials are also used in a variety of environmental remediation actions to stabilize seepage basin sludges, contaminated soils, and waste disposal sites.

In addition, cement-based materials are also used for underground waste tank and pipeline closures. The standard requirement for this application is subsidence prevention. Portland cement based grouts or pumpable, self-leveling, self-compacting backfills containing Portland cement are typically used for tank stabilization. Special grout or backfill formulations are also being designed to stabilize residual contaminants which may not have been removed from these tanks.

\section{ROADMAP MARKERS}

As evident by the above discussion, ceramic materials are essential in the current nuclear power industry. Future advances to make nuclear power more readily available for emerging markets, to develop proliferation-resistant fuels, and to deal with the waste byproducts generated by power generation will require on future material advances. Within the next year, significant advances will be made in the development of inert matrix fuels. These fuels, and their inherent proliferation resistance, will be critical in the peaceful application of nuclear power to meet a growing worldwide demand for electricity. In-reactor testing of promising compositions is underway or planned for the next 12 months. The results of this testing will guide future development. On the waste remediation side, significant progress is being made to address legacy materials from both weapons production and civilian nuclear power applications. In particular, legacy facilities are being decontaminated and decommissioned at an increasing rate. To safely and efficiently accomplish this closure, advances are needed to make current waste stabilization processes simpler, cheaper, and transportable. Several glass and ceramic processes for stabilization currently exist, and have been proven in operation, but most of the currently available technologies require bringing the waste materials to a heavily shielded, remotelyoperated facility. As decommissioning progresses, significant cost advantages could be achieved by bringing the immobilization technology to the decommissioning site, thus avoiding costly and potential hazardous transportation.

Within the next five years, the nuclear renaissance will hit 'full-stride' and several new reactor projects will be underway within the United States and dozens underway in developing 
economic markets (most notably India and China). To support this peaceful application of nuclear energy while alleviating proliferation concerns, inert matrix fuels will come to the forefront of materials research to support nuclear power. A stage-wise development of IMFs is required to support initial deployment in existing light-water reactors and subsequent deployment in advances fast and burner reactors. While increased proliferation resistance is a major 'policy driver' for use of IMFs, widespread deployment will require IMFs to be cost competitive with existing oxide fuel forms. While it is doubtful that IMFs will be cost neutral when compared to oxide fuels over the next five years, processing improvements will lower costs and improve deployment. As shown in Table 2, several oxide IMFs can be produced using the standard techniques (cold pressing an sintering) and equipment found in most commercial fuel fabrication facilities. Advanced nitride fuels currently require more costly preparation methods (such as hot pressing) making them less attractive for widespread application. Process improvements for nitride fuels that would allow more conventional processing methods would greatly improve cost competitiveness, and thus deployment, of advanced IMFs.

Over the next five years, advancements in waste stabilization processes will largely focus on increasing waste loading in high-level wasteforms in order to improve efficiency of facilities (i.e., increase production) and minimize the volume of material slated for geological repository disposal. Additionally, the increasing decontamination and decommissioning activities will drive development of new low-level waste immobilization technologies. As discussed above, significant savings can be achieved if these technologies are easily transportable from one site to the next. Additionally, material developments to the existing cementitious wasteforms will improve their processing characteristics and long-term durability. New wasteforms, such as geopolymers, also hold promise for near-term testing and deployment.

Within the next ten years, significant advancements will be made in advanced reactor technology and programs to build demonstration systems will be well underway. These reactors will require further fuel form developments beyond those described above. Next generation TRISO-based and other advanced fuels will be under development. Additionally, the International Thermonuclear Experimental Reactor (ITER) fusion reactor project will be well underway in Caderache, France. Fusion energy systems require high-temperature, harsh environments and ceramic materials will likely find multiple applications in areas such as plasma confinement.

Additionally, within a ten year period, the United States is expected to be in a demonstration of advanced spent nuclear fuel reprocessing technologies. This reprocessing demonstration has a two-fold purpose to demonstrate reprocessing flowsheets that do not separate $\mathrm{Pu}$ and to produce fuel for advanced reactor testing. Currently, both traditional aqueous and pyrometallurgical options are being considered. Ceramic materials are critical to both options. For aqueous processes, ceramic materials are used as structural materials in corrosive environments and also as end-product forms for both the recovered fuel products (in the form of oxides) and the stabilized byproducts (in mineralized forms generated by calcination or steam reforming). In the pyrometallurgical process, ceramics play an even more important role structurally as their high-temperature capability and chemical stability provide real advantages over metals or alloys. The fuel and byproducts are similar to those ceramic materials produced by aqueous flowsheets. 


\section{CONCLUSIONS}

As illustrated, ceramics play an important role in the nuclear cycle, from fuel fabrication to irradiation and reprocessing to safe encapsulation of nuclear waste products. Beyond that, development of ceramic materials and processes for nuclear applications has led to material and process enhancements that have improved conventional, commercially-available ceramics. For example, many of the processes and waste-forms developed to encapsulate and stabilize highlyradioactive nuclear wastes are now being employed to mitigate hazardous and toxic waste issues associated with numerous other industrial processes. Likewise, continued advancements made by the ceramic industry have resulted in an increasing number of new applications for ceramics in nuclear processes. Examples include; ceramic components in valves and pumps for improved radiation and corrosion resistance, ceramic or composite crucibles for handling highly radioactive materials, and improved, low-cost melters for encapsulation of nuclear waste products.

The increased use of nuclear power to meet growing worldwide energy demand poses even more opportunities for ceramic materials. As discussed, peaceful deployment of nuclear power requires increased reliance on fuels that are inherently proliferation resistant. Additionally, advanced fuel cycles will be increasingly 'closed,' relying on reprocessing to minimize wastes and eliminate proliferation concerns. Advances and widespread deployment of these technologies will require continued development of the ceramic materials that are central to the fuel form and byproduct stabilization portions of these fuel cycles. Finally, as further advances are made all leading to planned deployment of fusion energy systems in the 2050 timeframe, ceramics will be key enabling materials in numerous areas.

\section{REFERENCES:}

${ }^{1}$ Oak Ridge National Laboratory, "Nuclear Energy: Assuring Future Energy Supplies," ORNL Review, 35, 2002.

${ }^{2}$ United States National Academy of Sciences, "Management and Disposition of Excess Plutonium," (1994).

${ }^{3}$ R. Chawla and R.J.M. Konings, "Categorisation and Priorities for Future Research on Inert Matrix Fuels: An extended synthesis on the panel discussions," Progress in Nuclear Energy, 38, 455-458 (2001) 